not mattcr, is capable of definition. As Clerk Maxwell tells us that his statements contain all we know of matter and energy, it is clear that these are the only statements by way of definition which he conceives it advisable to give of them, and they are all he does give. I bappened to be one of the unfortunate Cambridge students whose first notions of matter and force were obtained from the "Treatise on the Dynamics of a Particle," and it was therefore a relief to me when I met with Kirchhoff's "Mechanik" in 1876 , and found the subjectivity of force clearly insisted on. That view of force was in the air of Berlin when I was a student there in 1879 . Kirchhoff's services in this matter are referred to with special emphasis on p. 139 of the "Grammar." A perfectly consistent view of force and matter had been published by Mach in 1883 . Why the fact that Prof. Tait put forward the "subjectivity of force" in a work of 1885 makes me therefore "a disciple of Prof. Tait," I fail to understand. This statement is the more astonishing, as Prof. Tait directly postulates the "objectivity of matter," but in the same work tells us that "matter is, as it were, the plaything of force." How subjective force can have an objective plaything, perhaps C. G. K. will inform us; but the statement clearly marks off the standpoint of the "Grammar" from that of Prof. Tait. Mass, according to the "Grammar," can only be defined as the ratio of mutual accelerations, and any attempt to connect it with the "quantity of matter" in a body is asserted to be unphilosophical. C. G. K. asks if a pas sage he quotes from Tait's "Properties of Matter" is not essentially the theory of "ether-squirts"? I reply $N o$, the words "constantly swallows up an amount proportional to its mass," or "at a rate proportional to its mass," sufficing to exclude the mutually enforced flows of ether on which the "Grammarian" bases his applications of ether-squirts to chemical and cohesive actions (American Fournal of Mathematics, vol. xiii., pp. 309-62). Ilad I ever read, or if read, re collected, Sir William Thomson's suggestion, it would have been referred to, and a reference to him will be introduced into later editions of the "Grammar,"

C. G. K. very skilfully tries to turn off the "Grammarian's" criticism of the Edinburgh school by representing it as an attack on Newton. The words in the "Grammar" are: "Remem. bering these points we will now turn to the version of the Neivtonian laws given by 7'hom son and Tait" (p. 38r). Force, say our writers, is any cause that tends to alter a body's natural state of rest, or of uniform motion in a straight line; but force, says Prof. Tait, is subjective, and corresponds to nothing which exists outside ourselves. Surely it is a "veritable metaphysical somersault" to then assert that it can be "applied in a straight line"? I fail completely to see how the view that force is subjective is consonant with the definitions and laws put forward by Thomson and Tait, and asserted by them to be Newtonian. With regard to Newton's own statements, I openly declare that, with all admiration for his genius, I doubt the logical sequence and accuracy of many of his statements with regard to the philosophical basis of dynamics. Those who would bind down all time to his views on matter, force, and motion, are much like the geometricians who think it impious to cast out Euclid from school-teaching. Both Euclid and Newton have handed down to us in their pages discoveries which will always form a portion of man's intellectual heritage, but the method in which those discoveries are presented will vary from age to age with in creasing clearness in man's conceptions of mental and physical processes.

Finally, C. G. K. remarks that my conclusions are "materialistic," by which term I suppose he means that he disayrees with them. As one of the chief objects of the "Grammar" is to cast the term matter forth from scientific language, it would have been more correct to say that my conclusions are "ideal. istic." I fear C. G. K. has a more supreme contempt than the majority of the countrymen of Reid and IIume for an accurate use of philosophical language.

Karl PEarson.

\section{Immunity of the African Negro from Yellow Fever}

THIs point, interesting to anthropologists, is raised anew by a writer on the history of epidemics (NATURE, June 16), who asks whether the alleged protection is supported by all recent authorities. Recent authorities are not so well placed for judging of this matter as the earlier; for the reason that immunity is not alleged except for the African negro of pure blood or unchanged racial characters, and that these conditions of the No. 1183 , VOL. 46$]$ problem have been much less frequently satisfied in the yellowfever harbours of the western hemisphere since the African slave trade ceased. However, there was a good opportunity in I866, during the disastrous yellow fever among the French troops of the Mexican expedition when they lay at Vera Cruz. Among them was a regiment of Nubians, who had been enlisted for the expedition by permission of the Khedive : that regiment had not a single case of yellow fever all through the epidemic. The African negro regiment brought over from the French colonies of Martinique and Guadeloupe had two or three cases, with, I think, one death. The rest of the troops, including Frenchmen, Arabs from Algeria, native Mexicans and Creoles, had no immunity whatever, but, on the other hand, a most disastrous fatality. The medical officers of the French service have recorded the facts principally in the Archives de Médecine Navale, their conclusion as to racial immunity being the same that has passed current among the earlier authorities as a truth of high general value (admitting, of course, of exceptions in special circumstances), and a truth that has never, so far as I know, been formally controverted by anyone, although other points concerning yellow fever have been the subject of as obstinate controversy as those touching small-pox itself. The experiences of the French at Gorce, a town with ten times as many negroes as whites, exactly confirmed those of Vera Cruz in the same year (Arch. de Mád. nav., ix. 343).

The immunity of the African negro from yellow fever has become a paragraph in some anthropological text-books. It is from the anthropologist; and not from medical authurities, that Darwin cites the fact in his "Descent of Man," adding an original theory of the immunity, which he $u$ as unable to establish after much inquiry. His theory, I need hardly say, was not that " negroes in infancy may have passed through some disease too slight to be recognized as yellow fever,"-whatever that may mean-"but which seems to confer immunity." The theory, however, is another story, or "another voume," as the writer just cited is pleased to suggest; and as for the historical fact of immunity, no one denies it, unless it be Dr. Pye Smith in his recent Iumleian lectures (Lancet, A pril 23, 1892, p. 901), who gives no reasons.

It is unfortunate that the anthropologists (Darwin am.no them) should have introduced one element of dubiety in placing mulattoes on the same footing, in respect of immunity, as negroes of pure descent, and another in mixing up malarial or climatic fevers with yellow fever. June 20.

The Line Spectra of the Elements.

I SEE by Prof. Stoney's letter that I have not yet succeeded in making myself understood, as he does not enter on the subject of my objection. A function of the time may well, with any assigned degree of accuracy and for any length of time, be approximately represented by a sum of circular functions, and nevertheless the periods, amplitudes, and phases may not approach definite values when the length of time for which the approximation is to hold good is increased indefinitely. I think this is quite clear from the example I have given in my last letter (p. 100), and it is not necessary to write out other examples. Now, Prof. Stoney shows how one may find by Fourier's theorem the amplitude;, periods, and phases of a sum of circular functions if one only knows the values of the sum. This deduction is not new to me. I worked out the same equations in a slightly different form, when Prof. Stoney's first letter made me further think about the subject. The deduction does also apply to functions that are approximately represented by a sum of circular functions, but only und'r the restriction that the time for which the approximation hulds good is long in comparison to the longest period of the circular functions. In chapter iv. of his paper "On the Cause of Double Lines, \&.c." (Transactions of the Royal Dublin Society, 1891), Prof. Stoney should have added this restriction. Then the question would naturally have arisen how the restriction follows frum Prof. Stoney's hypothesis on the origin of the line spectra. I do not venture to say that it does not, but the author would have to prove it.

Technische Hochschule, Hannover.

C. RUNG.

\section{The Nitric Organisms.}

I MUCH regret to learn from your last issue that Mr. Waring. on considers that I failed to do justice to his work on this 